\title{
A Study of the Composition and Dissolution of Jianshui Purple Pottery in Yunnan, China
}

\author{
Chang Liu ${ }^{1, *}$, Heng $\mathrm{Xie}^{2}$, Lei $\mathrm{Nie}^{3}$, Hong Wang ${ }^{4}$ and Yuanyuan $\mathrm{He}^{3}$ \\ 1 College of Art and Design, Jilin Jianzhu University, Changchun 130021, China \\ 2 Jianshui Purple Pottery Research Association, Jianshui 654300, China; 13908733711@163.com \\ 3 College of Construction Engineering, Jilin University, Xi Min Zhu Street, Changchun 130026, China; \\ nielei@jlu.edu.cn (L.N.); hyy20@mails.jlu.edu.cn (Y.H.) \\ 4 College of Civil Engineering, Guizhou University, Guiyang 550025, China; hwang23@gzu.edu.cn \\ * Correspondence: changtongwuzu1985@163.com
}

Citation: Liu, C.; Xie, H.; Nie, L.; Wang, H.; He, Y. A Study of the Composition and Dissolution of Jianshui Purple Pottery in Yunnan, China. Crystals 2021, 11, 1034. https://doi.org/10.3390/cryst 11091034

Academic Editor: Francisco M. Morales

Received: 25 July 2021

Accepted: 26 August 2021

Published: 28 August 2021

Publisher's Note: MDPI stays neutral with regard to jurisdictional claims in published maps and institutional affiliations.

Copyright: (c) 2021 by the authors. Licensee MDPI, Basel, Switzerland. This article is an open access article distributed under the terms and conditions of the Creative Commons Attribution (CC BY) license (https:// creativecommons.org/licenses/by/ $4.0 /)$.

\begin{abstract}
Pottery is a gem in the history of human civilization and a crystallization of human wisdom. Yunnan Jianshui purple pottery is one of the four famous types of pottery in China, with a long history and superb craftsmanship. Used as tableware, research on the composition and element dissolution of pottery is extremely significant for production and health. This paper takes Jianshui purple pottery as its research object, samples its raw ores and finished products, and conducts X-ray fluorescence, scanning electron microscopy, inductively coupled plasma mass spectrometry experiments, and dissolution tests. The chemical composition, microstructure, and trace element concentrations of pottery before and after firing were measured. Results show that the dissolution of purple pottery under various use scenarios is low and meets health requirements. Combined with the characteristics of purple pottery, the composition changes and the mechanism of change before and after firing are discussed, which can be used as the theoretical basis for improving pottery production in the future.
\end{abstract}

Keywords: traditional potteries; firing process; chemical composition; trace element dissolution; production improvement

\section{Introduction}

Pottery, as an exquisite craft, is a gem of human civilization. It is a utensil mainly made of clay, which was usually used as container of food or water in ancient times. Today, the mass production of exquisite pottery is mainly for decorative crafts or tea sets. According to records, the history of human production of pottery extends more than 10,000 years, consequently pottery is of extremely important cultural and historic significance [1]. The origin of pottery occurred independently in two regions, Northern Africa and East Asia, and spread to surrounding areas [2]. The unearthed pottery records the development of human production and labor skills. They are also carriers of culture and history and have important archaeological and artistic value. Many historic potteries are collected in museums as cultural relics, and the history of human activities in a certain period is explained through the stories behind them. Pottery was originally produced as practical cooking utensils and containers, and its appearance was crude because of the limitations of people's production technology. With the development of society and production levels, the aesthetics of pottery was gradually improved. The complexity of the shape of the pottery and the difficulty of the manufacturing process also reflected the development of human production skills. The pottery unearthed in various periods also reflected the local production level and productivity of the period to a certain extent. At present, most research on pottery is based on archaeology, history, and art [3]. There is relatively little research on the physical properties of pottery and the chemical composition. Having a full understanding of the chemical composition of the pottery's original ores 
and finished products and analyzing the difference before and after firing are helpful to further study the pottery making process and to improve the pottery raw material ratio and manufacturing process.

There are some studies on pottery technology and craftsmanship, and they analyze the compositions and firing skills to better know the development of pottery. McGorven conducted a chemical composition analysis on the pottery pieces of clay pots unearthed at the Jiahu site in Wuyang, Henan. The test results showed that this pottery was used to brew rice wine [4]. M.S. Tite measured the firing temperature of pottery of different eras in Turkey, Iraq, Nigeria, Britain, China, and other regions using a thermal expansion method, and concluded that the original firing temperature of the pottery was $620-1200{ }^{\circ} \mathrm{C}$ [5]. Meng researched pottery of all ages in the Haidai area and summarized its evolution. He measured the original firing temperature of pottery by the thermal expansion temperature measurement method and combined the physical properties to analyze the history of pottery technology development [6]. Yu determined the chemical composition, physical phase, and microstructure of pottery samples unearthed from Yongkang Huxi, Miaoshan, Zhejiang Province, and detailed the raw materials and manufacturing process [7]. Wang and Chen analyzed the chemical composition and physical properties of the pottery unearthed from the Beiqian site and pointed out that $\mathrm{SiO}_{2}$ and $\mathrm{Al}_{2} \mathrm{O}_{3}$ were the main chemical compositions and determined the hardness of the pottery [8]. Through the analysis of the chemical composition of pottery, the classification of pottery, and the development process of pottery production technology in primitive society can be studied, which is of important archaeological significance [9]. Guan studied the craftsmanship and raw material mineral rock characteristics of Jianshui purple pottery in Yunnan, Qinzhou Nixing pottery in Guangxi, and Rongchangan pottery in Chongqing. The chemical composition, microstructure, and trace elements of the raw materials of pottery were measured and observed [10]. It can be seen that this research simply investigated the compositions and production process of pottery, the difference between the raw ores and finished products is not involved. The quality of the raw ores and the proportion of clay materials directly affect the quality of the pottery products. Understanding the production process of pottery and the chemical composition of the original ores, and investigating the change in the chemical composition of the pottery from raw materials to finished products can provide a scientific basis for the study of pottery technology. According to such research, a deeper understanding of the composition and physical properties of pottery can be obtained to better understand the pottery production technology and to improve it.

Yunnan Jianshui purple pottery is one of the four types of famous pottery in China, produced in Jianshui County, Yunnan Province, China. Jianshui purple pottery has a history of about 3500 years, and its name is derived from its origin and color [11]. In the 21st century, the pottery-making skills of Jianshui gradually flourished and were listed as an intangible cultural heritage [12]. Traditionally, the main production steps of Jianshui purple pottery are shown in Figure 1. The raw materials of Jianshui purple pottery are argillaceous siltstones, and the mineral composition of it is mainly quartz, illite, kaolinite, hematite, and so on. Its firing temperature is $1120-1180{ }^{\circ} \mathrm{C}$, and the temperature difference of $60{ }^{\circ} \mathrm{C}$ is produced by the different hardness and firing requirements of the clay. There are special process requirements for clay preparation and embryo production during the high temperature firing of Jianshui purple pottery, which also gives it unique and excellent performance. Firstly, the hardness of Jianshui purple pottery can reach 6-7 degrees on the Mohs scale and through abrasive polishing can make the pottery as warm as jade, as clean as a mirror, with gorgeous ornamental properties. Secondly, Jianshui purple pottery is nontoxic, tasteless, and harmless to human health [11]. Thanks to the continuous improvement of the manufacturing process and level, Jianshui purple pottery's actual uses are hiding tea without mold, storing rice without insects, planting flowers without rotten roots, and it is a widely used, healthy, and delicate pottery product. 


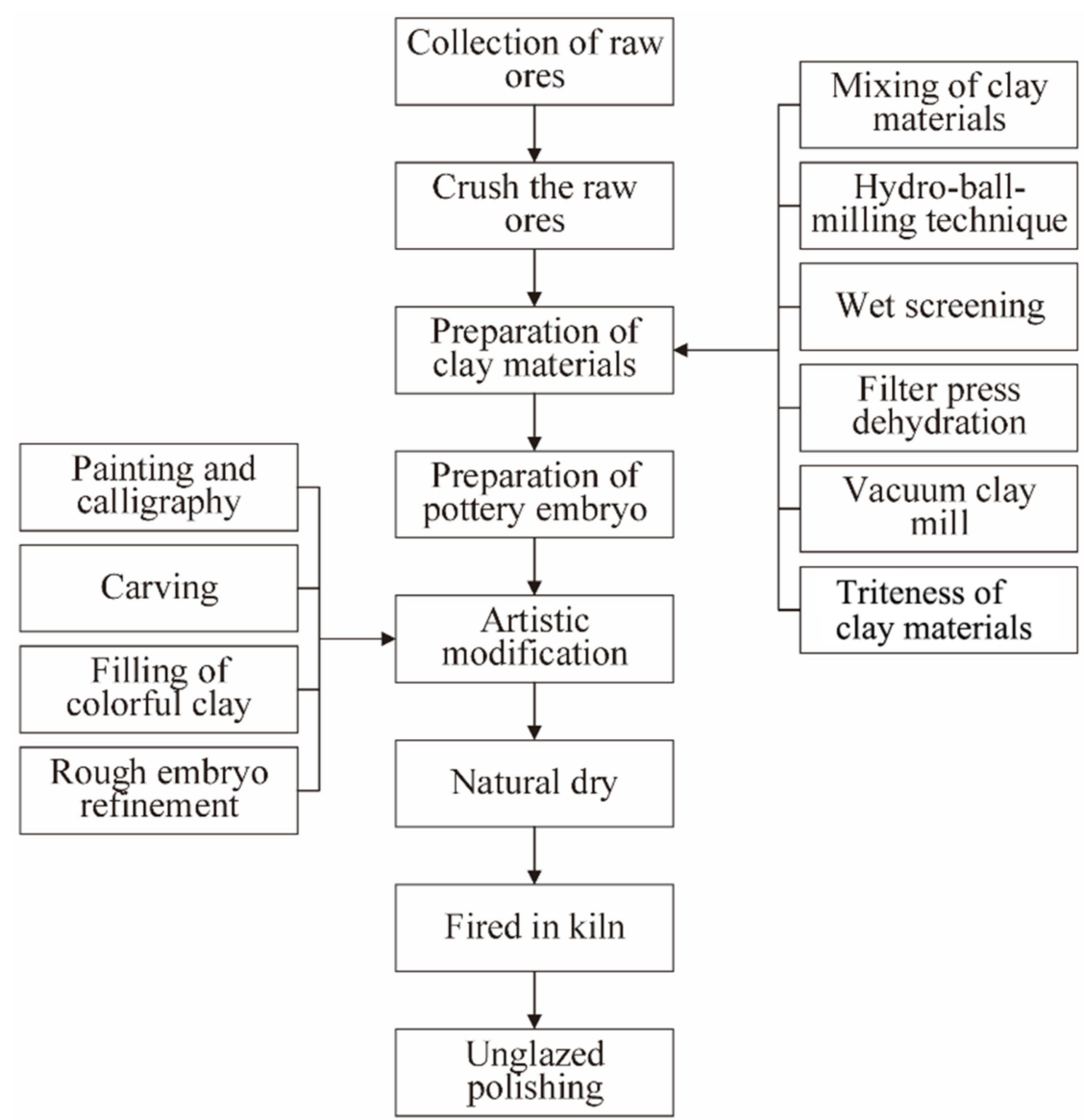

Figure 1. The production process flow diagram of Jianshui purple pottery.

This paper takes Yunnan Jianshui purple pottery as its focus, and conducts X-ray fluorescence, scanning electron microscopy (SEM), energy spectrum analysis (EDS), and inductively coupled plasma mass spectrometry (ICP-MS) experiments on its raw ores, mixed clay, and finished product samples, respectively. Trace element dissolution tests of pottery cups were conducted to verify its safety as cookware and container. Comparing the trace element dissolution from purple pottery cups with the national standard, it was confirmed that Jianshui purple pottery is safe as a food-contact appliance. In the future development of pottery, this research can be used as a theoretical basis for technological improvement.

\section{Materials and Methods}

\subsection{Study Area}

Jianshui County is located in the eastern part of Yunnan Province, China. The geographic coordinates are $23^{\circ} 37^{\prime} \mathrm{N}, 102^{\circ} 50^{\prime} \mathrm{E}$, and the total area is 3940 square kilometers (Figure 2). The area is located in a low-latitude area, the Tropic of Cancer traverses the southern boundary, with a long light time, a long frost-free period, and a high effective accumulated temperature. Affected by seasonal and topographic changes, it presents a three-dimensional climate characteristic of hot and rainy summers and mild and rainy winters. The soil in Jianshui area is divided into eight soil types including yellow brown soil, yellow soil, red soil, dry red soil, Lateritic red soil, purple soil, alluvial soil, and paddy soil, 10 subcategories, 17 soil genera, and 49 species. 


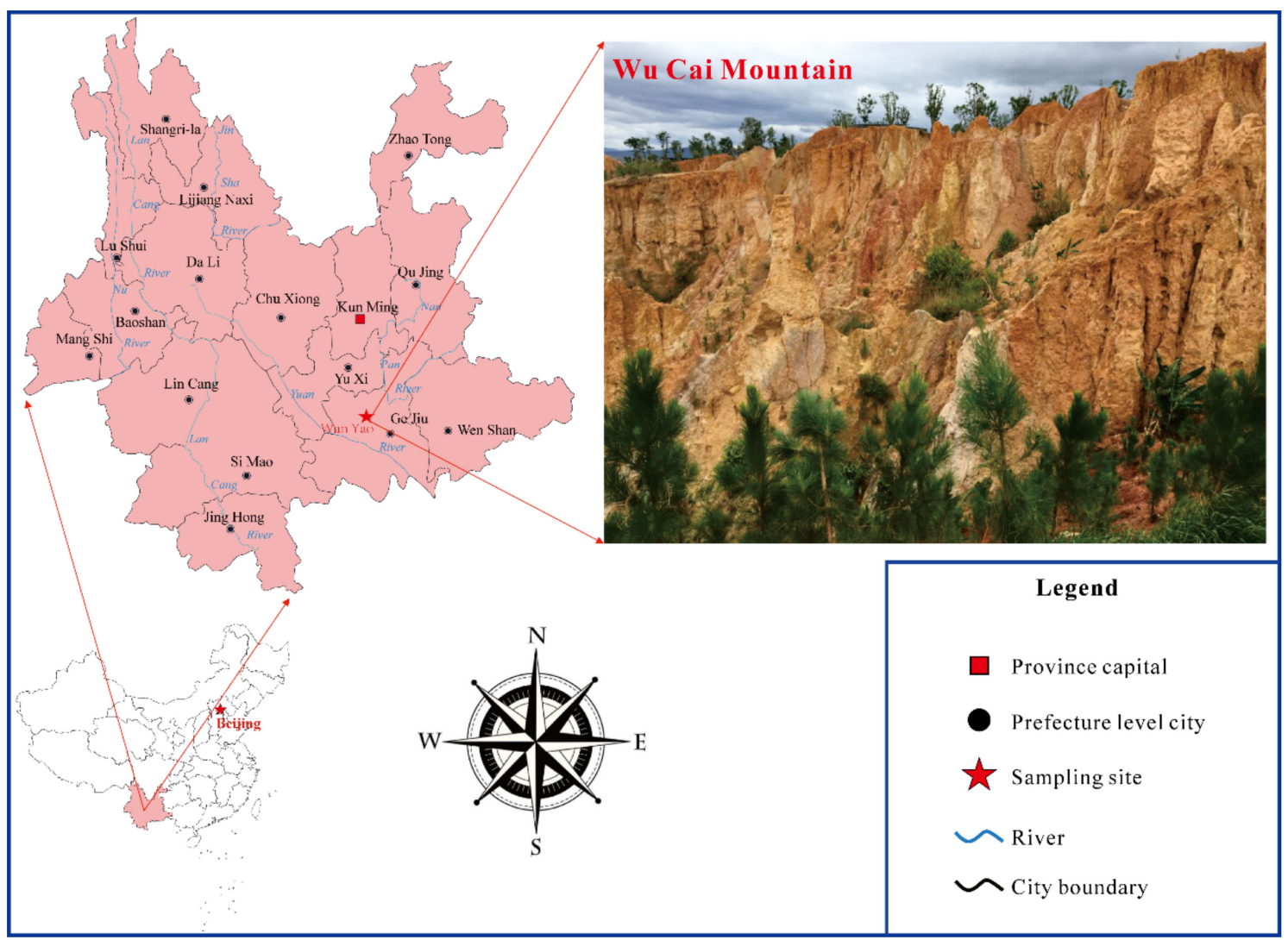

Figure 2. Geographical location of Jianshui County, Yunnan.

\subsection{Sampling and Experimental Methods}

In this study, the raw materials, mixed clay, and finished products of Yunnan Jianshui purple pottery were sampled separately, and X-ray fluorescence, scanning electron microscopy (SEM), energy spectrum analysis (EDS), and inductively coupled plasma mass spectrometry (ICP-MS) experiments were conducted. The instrument used for the X-ray fluorescence (XRF) measurements was a ZSX Primus II X-ray fluorescence spectrometer made in Japan, and the elemental detection range was element 9 (F)-element 92 (U). The sample was first ground into powder and then calcined at $1000{ }^{\circ} \mathrm{C}$. The LOI value was calculated by comparing the mass difference before and after calcination. The calcined samples were used for XRF measurements to derive the values of the individual oxide content. SEM observations and EDS analysis used the JSM-6700 field emission scanning electron microscope. The $\mathrm{X}$ series II inductively coupled plasma mass spectrometer of American Thermoelectric Corporation was used to detect trace elements in samples by ICP-MS measurements. The above experiments were completed in the laboratory of Jilin University.

The raw materials of Jianshui purple pottery are five kinds of clay, which are red, yellow, cyan, purple, and white, called "five-colored soil". Raw materials are mainly produced in Wanyao Village near Jianshui County, distributed in tertiary strata. Purple pottery clay mixture is the intermediate product, it is a mixture of five kinds of soil in a specific ratio. There are two kinds of purple pottery, which are reducing flame product and oxidized flame product. In Table 1 and Figure 3, the characteristics of five raw materials, mixture, and two finished products are presented. 


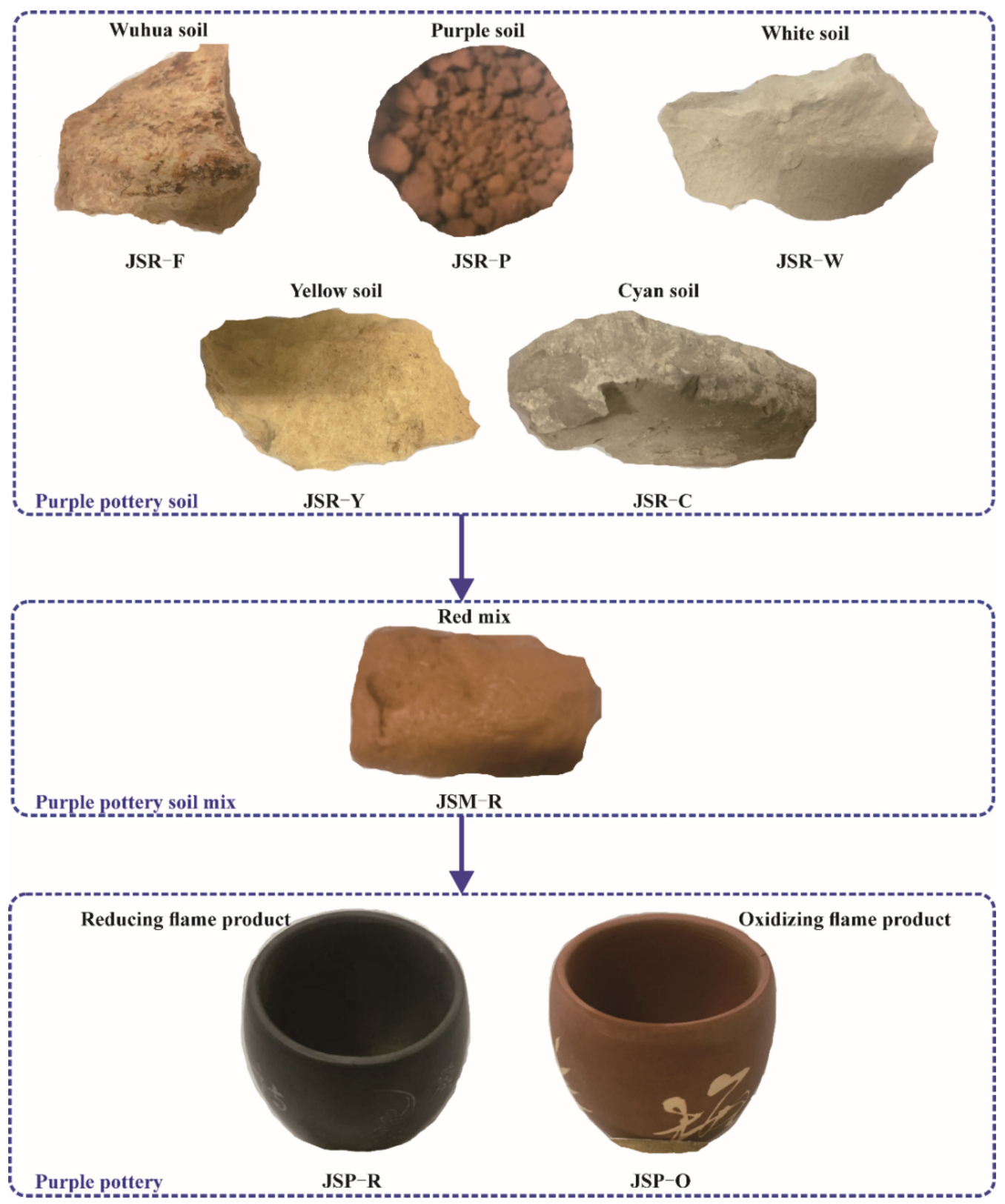

Figure 3. Picture of Jianshui purple pottery raw materials and finished product samples.

The main production process of Jianshui purple pottery can be divided into five steps. Firstly, five-colored clay is mined, it will be soaked in water, filtered several times, and then air-dried for use. After this step, impurities and sand in the clay are almost completely removed, and each type of clay is pure in color and delicate in texture. Secondly, the five kinds of clay materials are mixed and stirred to obtain clay mixtures. Generally, the standard of the raw material ratio is according to local traditions as shown in Table 2. However, potters will adjust it according to their experience and actual situation. After much rubbing, the mixed clay is compacted to make it dense. This step is very important to prevent gas remaining in the mixture. If gas remained in the pottery body, it would cause the failure of the firing process because of gas expansion. Thirdly, potters shape the semi-wet clay into a desired shape on a rotating disc, and then air-dry it. Fourthly, the artist sculpts or paints on the pottery body obtained in the previous step to beautify it. Lastly, the pottery body is put into the kiln for firing, the temperature is about $1120-1180{ }^{\circ} \mathrm{C}$. The fired pottery needs to be polished many times and finally becomes exquisite utensils. 
Table 1. Experimental sample description of raw materials and finished products of purple pottery.

\begin{tabular}{|c|c|c|}
\hline Sample Type & Encoding & Description of Sample Characteristics \\
\hline \multirow{5}{*}{ Purple pottery soil } & JSR-F & $\begin{array}{l}\text { Commonly known as Wuhua soil or red soil, opencast mining, the sample is composed of } \\
\text { three main colors of yellow, white, and red, a massive structure. }\end{array}$ \\
\hline & JSR-P & $\begin{array}{l}\text { Commonly known as purple soil, opencast mining, it is an auxiliary raw material for } \\
\text { pottery making. The weathered surface of the sample is dark red, and the fresh surface is } \\
\text { purple, with a block structure. The soil is delicate and easy to dye. }\end{array}$ \\
\hline & JSR-W & $\begin{array}{l}\text { Commonly known as white soil, openpit mining, the weathering surface of the sample is } \\
\text { white, with a massive and dense structure. }\end{array}$ \\
\hline & JSR-Y & $\begin{array}{l}\text { Commonly known as yellow soil, openpit mining, it is the auxiliary raw material for } \\
\text { making pottery. The weathered surface of the sample is yellow, with a massive and dense } \\
\text { structure, fine and easy to dye. }\end{array}$ \\
\hline & JSR-C & $\begin{array}{l}\text { Commonly known as cyan soil, openpit mining, the weathering surface of the sample is } \\
\text { cyan, with a massive and dense structure, with fine and smooth texture. }\end{array}$ \\
\hline $\begin{array}{l}\text { Purple pottery } \\
\text { clay mixture }\end{array}$ & JSM-R & Red mix: it is made of a variety of purple pottery soil mixed and milled, and the clay is fine. \\
\hline \multirow[t]{2}{*}{ Purple pottery } & JSP-R & $\begin{array}{l}\text { Reducing flame product: the combustion of oxygen molecules in the flame is not clean } \\
\text { when firing pottery, and there are relatively more carbon molecules. The firing temperature } \\
\text { is about } 1140^{\circ} \mathrm{C} \text {. }\end{array}$ \\
\hline & JSP-O & $\begin{array}{l}\text { Oxidizing flame product: when firing pottery, oxygen molecules are abundant and carbon } \\
\text { molecules are few, and the firing temperature is around } 1160{ }^{\circ} \mathrm{C} \text {. }\end{array}$ \\
\hline
\end{tabular}

Table 2. Standard ratio of raw materials for red mixture.

\begin{tabular}{ccccccc}
\hline Purple Pottery Soil & JSR-F & JSR-P & JSR-W & JSR-Y & JSR-C & Sum \\
\hline JSM-R & $50 \%$ & $10 \%$ & $15 \%$ & $15 \%$ & $10 \%$ & $100 \%$ \\
\hline
\end{tabular}

Because the raw material is muddy soil, not sandy, and it has been filtered many times, it is very delicate. The permeability of the finished product is related to the fineness of the clay and the sintering degree of the pottery. Sintering refers to the transformation of powdery materials into dense bodies at high temperatures. Martin-Marquez, J et al. studied the sintering of porcelain clay tiles and found that the raw material composition contained albite, microcline, and muscovite as fluxes, which started to decompose at low temperatures (400-800 ${ }^{\circ} \mathrm{C}$ interval). During firing, the amorphous phase increased continuously, resulting in a decrease in open porosity. However, the viscosity of the liquid phase increased due to the formation (at $1100{ }^{\circ} \mathrm{C}$ to $1230^{\circ} \mathrm{C}$ ) and crystallization of mullite and the dissolution of quartz in the liquid phase $\left(1230^{\circ} \mathrm{C}\right)$. This led to an increase in the compact porosity before the open porosity disappears totally. Therefore, there exists a best temperature range where the open porosity value is the lowest and the linear shrinkage is the highest, making the sample after sintering action homogeneous and free of defects, such as holes, bubbles, or cracks [13,14]. People have been using this process for a long time to produce ceramics, powder metallurgy, refractory materials, ultra-high temperature materials, etc. Under high temperature, the crystals of clay particles in the purple pottery embryo grow. The solid particles are interlinked and the voids (pores) and grain boundaries tend to decrease. Further, through the transfer of matter, its total volume shrinks, the density becomes higher, and the strength is also greatly increased.

\subsection{Data Analysis Methods}

Origin 9.0 software was used to perform linear regression analysis. The linear fitting of chemical compositions was mainly to analyze the proportion between ceramic raw materials, mixtures, and finished products. 


\section{Experimental Part}

\subsection{Chemical Composition}

As shown in Table 3, $\mathrm{SiO}_{2}, \mathrm{Al}_{2} \mathrm{O}_{3}, \mathrm{Fe}$ (iron oxides), and $\mathrm{K}_{2} \mathrm{O}$ are the main chemical oxides of Yunnan Jianshui purple pottery, both in the raw materials and finished products. The content of $\mathrm{SiO}_{2}$ is the highest. Except for JSR-P at 35.77\%, the proportion of $\mathrm{SiO}_{2}$ in each sample is higher than $60 \% . \mathrm{Al}_{2} \mathrm{O}_{3}$ is the second most abundant oxide, which in JSR-P is $31.55 \%$ and the other samples' contents are between $10 \%$ and $20 \%$. The content of Fe in JSR-P is as high as $17.27 \%$, and it is about $1 \%$ to $8 \%$ in other samples. $\mathrm{K}_{2} \mathrm{O}$ content in samples is $0.3 \%$ to $2.88 \%$, the other chemical compositions are lower than $1 \%$. The test results of the chemical compositions are consistent with the study of Guan [10]. In addition, according to Table 3, it can be seen that the raw material samples except JSR-P contain similar chemical compositions, which are about $65 \% \mathrm{SiO}_{2}, 15 \% \mathrm{Al}_{2} \mathrm{O}_{3}, 3 \% \mathrm{Fe}, 2 \% \mathrm{~K}_{2} \mathrm{O}$, and others. The chemical compositions of JSR-P are different, which are reflected as a relatively higher content of $\mathrm{Al}_{2} \mathrm{O}_{3}$ and $\mathrm{Fe}$ and a lower content of $\mathrm{SiO}_{2}$ and $\mathrm{K}_{2} \mathrm{O}$. There is almost no chemical composition difference between the two finished product samples (JSP-O, JSP-R).

Table 3. XRF test results of the chemical compositions of experimental samples ( $\mathrm{w} t \%)$.

\begin{tabular}{ccccccccccccc}
\hline Sample No. & $\mathbf{S i O}_{\mathbf{2}}$ & $\mathbf{A l}_{\mathbf{2}} \mathbf{O}_{\mathbf{3}}$ & $\mathbf{T F e}$ & $\mathbf{C a O}$ & $\mathbf{M g O}$ & $\mathbf{K}_{\mathbf{2}} \mathbf{O}$ & $\mathbf{N a}_{\mathbf{2}} \mathbf{O}$ & $\mathbf{T i O}_{\mathbf{2}}$ & $\mathbf{P}_{\mathbf{2}} \mathbf{O}_{\mathbf{5}}$ & $\mathbf{M n O}$ & $\mathbf{L O I}$ & $\mathbf{S u m}$ \\
\hline JSM-R & 63.45 & 17.59 & 7.88 & 0.43 & 0.77 & 2.64 & 0.08 & 1.02 & 0.07 & 0.04 & 5.76 & 99.73 \\
JSP-O & 69.95 & 18.81 & 5.94 & 0.32 & 0.74 & 2.7 & 0.11 & 1.11 & 0.07 & 0.03 & 0.2 & 99.96 \\
JSP-R & 69.67 & 18.87 & 5.93 & 0.38 & 0.73 & 2.76 & 0.14 & 0.99 & 0.06 & 0.04 & 0.22 & 99.79 \\
JSR-C & 74.60 & 15.66 & 0.94 & 0.08 & 0.5 & 1.79 & 0.07 & 1.41 & 0.03 & 0.01 & 4.91 & 100.00 \\
JSR-F & 69.97 & 17.09 & 2.85 & 0.14 & 0.73 & 2.87 & 0.07 & 0.97 & 0.04 & 0.02 & 5.04 & 99.81 \\
JSR-P & 35.77 & 31.55 & 17.27 & 0.15 & 0.49 & 0.3 & 0.06 & 1.42 & 0.17 & 0.05 & 12.75 & 99.97 \\
JSR-W & 75.44 & 14.59 & 1.26 & 0.14 & 0.57 & 2.41 & 0.07 & 1.26 & 0.03 & 0.02 & 4.21 & 100.00 \\
JSR-Y & 77.33 & 11.63 & 4.08 & 0.02 & 0.38 & 1.78 & 0.08 & 0.96 & 0.04 & 0.01 & 3.55 & 99.85 \\
\hline
\end{tabular}

TFe means total Fe, LOI means loss on ignition.

\subsection{SEM and EDS Analysis}

As shown in SEM images of raw material samples, the minerals in the samples were mainly presented in flake and granular forms (Figure 4). Flaky minerals were mainly clay minerals, with irregular shaped edges which are surrounded by silk-like and wavy projections. Large irregular or polygonal crypt-like pores were extremely developed and evenly distributed [15]. Therefore, the clay not only had a strong gas adsorption capacity but also had a rich free gas storage space. The particle size was about 2-10 $\mu \mathrm{m}$, which was characterized by a high content of K. Granular particles were quartz, with a size from $5 \mu \mathrm{m}$ to $25 \mu \mathrm{m}$, distributed among the clay minerals.

SEM images of the mixture samples showed that the pores and bubbles were small and sparsely distributed (Figure 5). This was because after mixing, the five raw materials were stirred and compacted, the content of water was rich, and the interior texture became denser.

In the SEM images of the finished pottery products, many sparsely distributed holes and bubbles could be clearly seen (Figure 6). The clay minerals were sintered together and difficult to discern. The reason for the holes and bubbles was that the gas in the pottery body had not been exhausted during the firing process, or gasses such as $\mathrm{CO}$ and $\mathrm{CO}_{2}$ were generated from raw material clay minerals at high temperatures. Some of the raw materials decomposed and some of them melted during sintering, reacting together and forming new phases, which was another reason for pore formation. The pores can be larger too because a higher temperature lowers the viscosity of the liquid phase. It has been found that quartz grains undergo $\alpha-\beta$ phase transition at $573{ }^{\circ} \mathrm{C}$, which can induce cracks in quartz grains [16,17]. Meanwhile, the accompanied expansion of quartz grains generates tensile stresses in the surrounding matrix. During cooling, the equivalent contraction of quartz grains make the quartz particles no longer bonded to the clay matrix leaving pores in the pottery $[18,19]$. The higher the temperature during the firing process the more and 
larger the pores form. This is because the consolidation process is faster and gas is more difficult to expel [20]. As shown in the SEM image, the pores and bubbles in JSP-O were denser than JSP-R because the firing temperature of JSP-O was relatively higher than that of the latter.
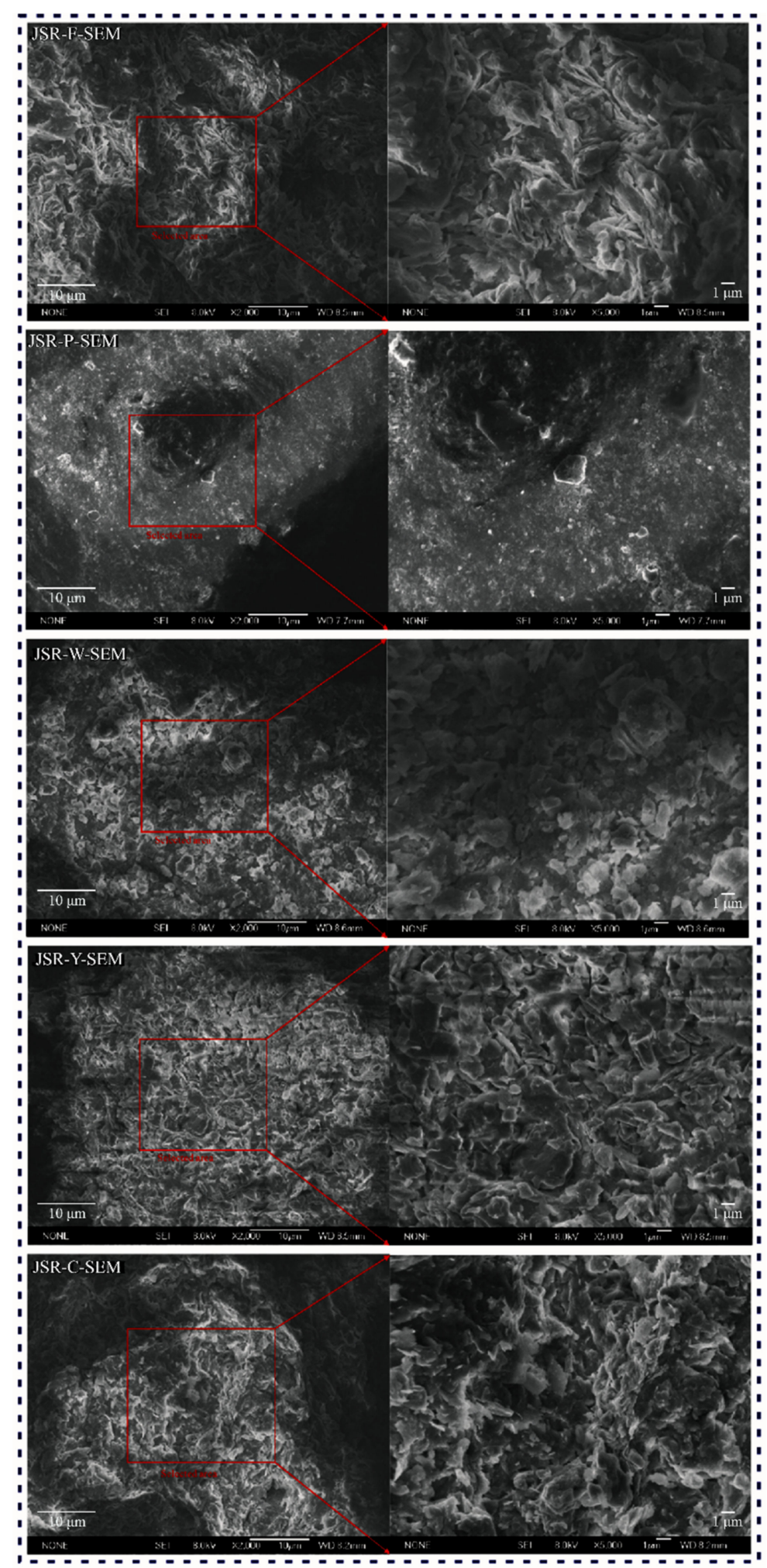

Figure 4. SEM images of pottery raw material samples. 


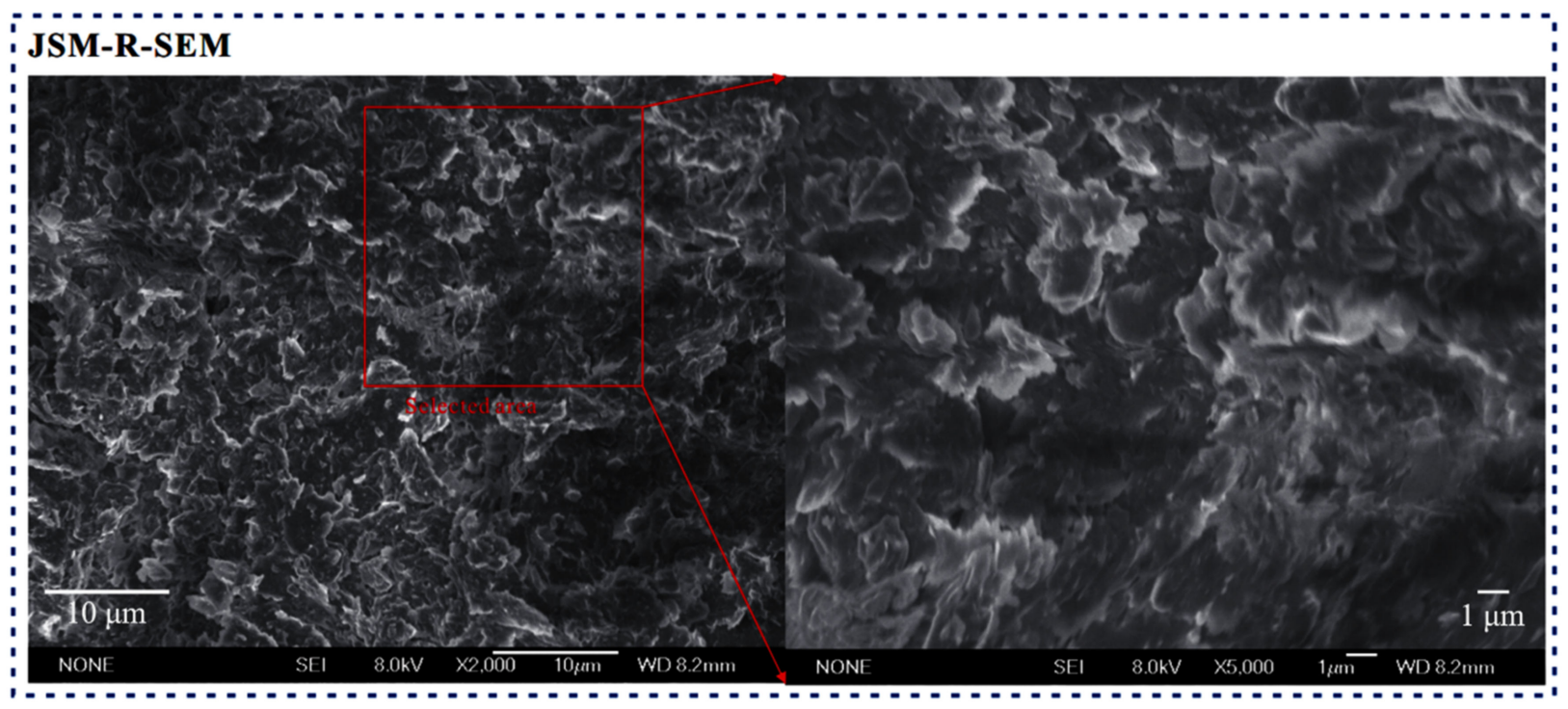

Figure 5. SEM and EDS analysis results of clay mixture sample.

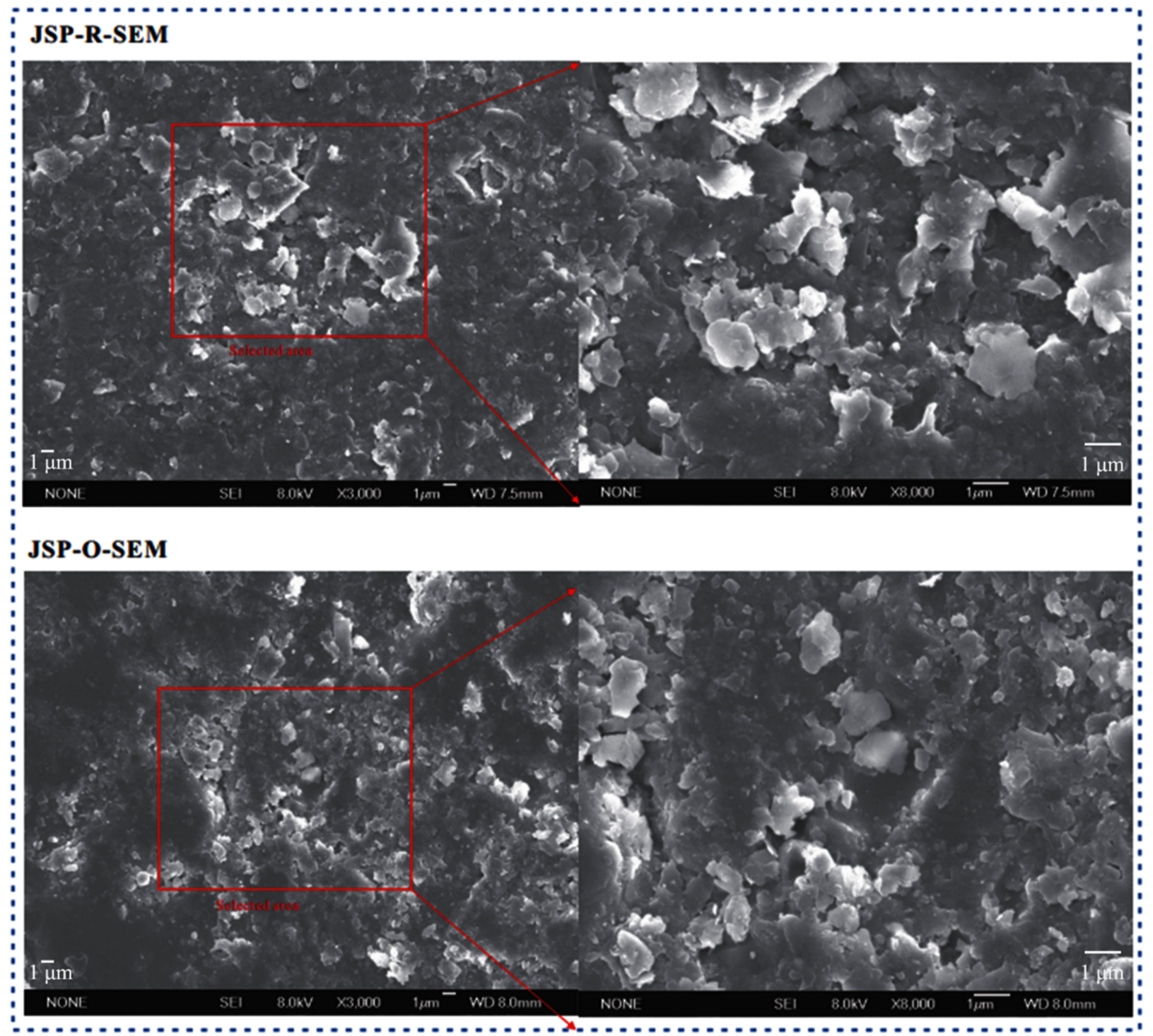

Figure 6. SEM images of finished pottery samples. 
Energy spectrum analysis (EDS) is generally used with scanning electron microscopy (SEM) to determine the element content of a point in the sample, and the principle of elemental analysis is based on the fact that different elements produce different characteristic X-rays when exposed to high energy electron beams. Similar to the results of chemical compositions, the EDS analysis results of JSR-P were different from the other raw ore samples (Figure 7). Since EDS is an elemental analysis of a particular point, we measured 5-10 random points for each sample. The statistics of their elemental content were plotted in Figure 7, using the boxplot method. In the boxplot, the upper and lower points are the maximum as well as the minimum values, the upper and lower edges of the box are the upper and lower quartiles, the middle horizontal line is the median, and the middle point is the average value. $\mathrm{O}, \mathrm{Si}$, and $\mathrm{Al}$ are the three elements with the highest content, and the JSR-P sample contains much more Fe and less Si and K than others. The most abundant element in the finished pottery product samples is $\mathrm{O}$, followed by $\mathrm{Si}$ and Al. The content of $\mathrm{K}$ in both samples is about $2 \%$, and the content of $\mathrm{Fe}$ is about $5 \%$. The high $\mathrm{Fe}$ content and the sufficient oxidation reaction during the firing process of the oxidizing flame product are the reasons why the color of the JSP-O pottery is red.
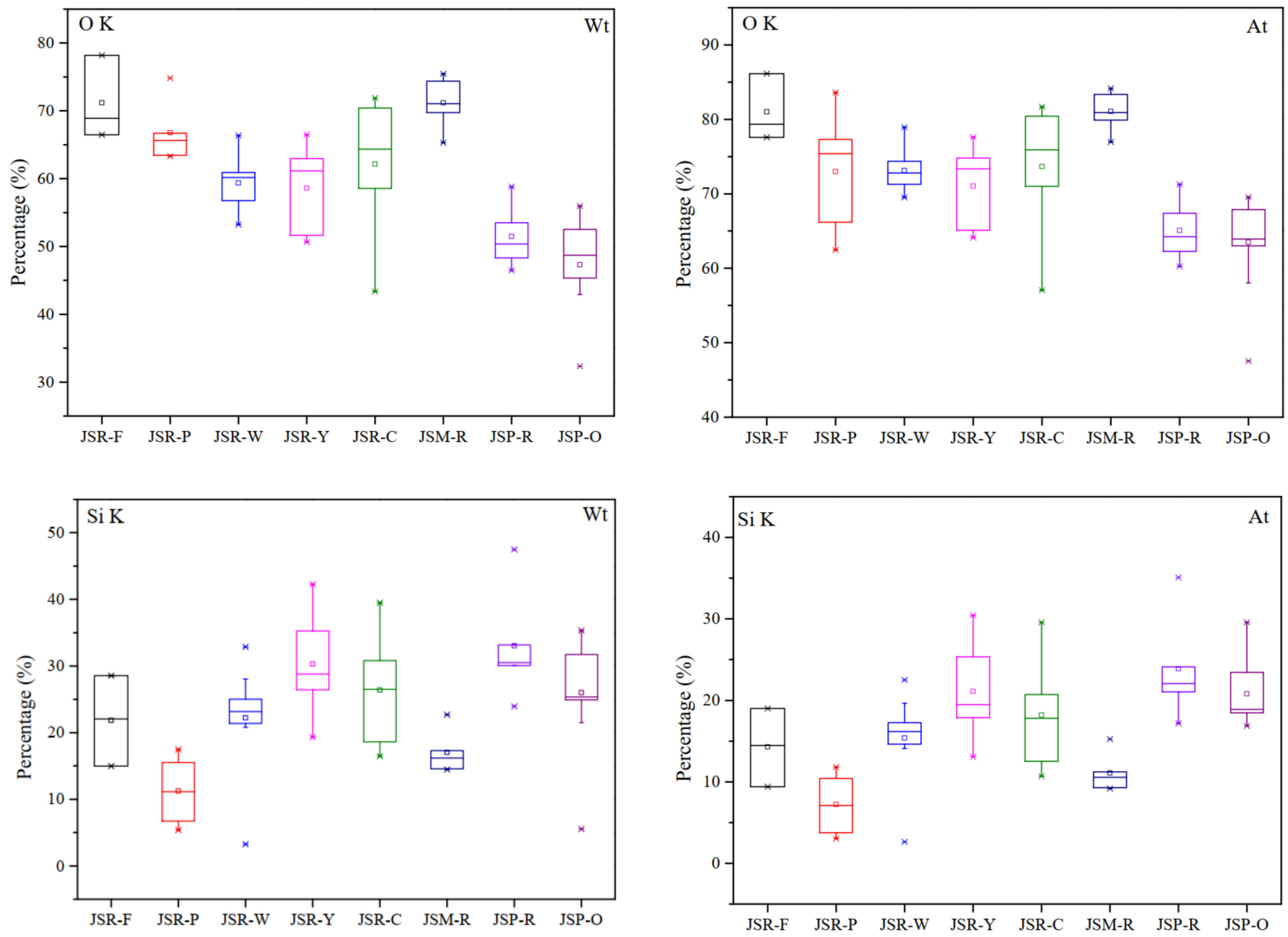

Figure 7. Cont. 

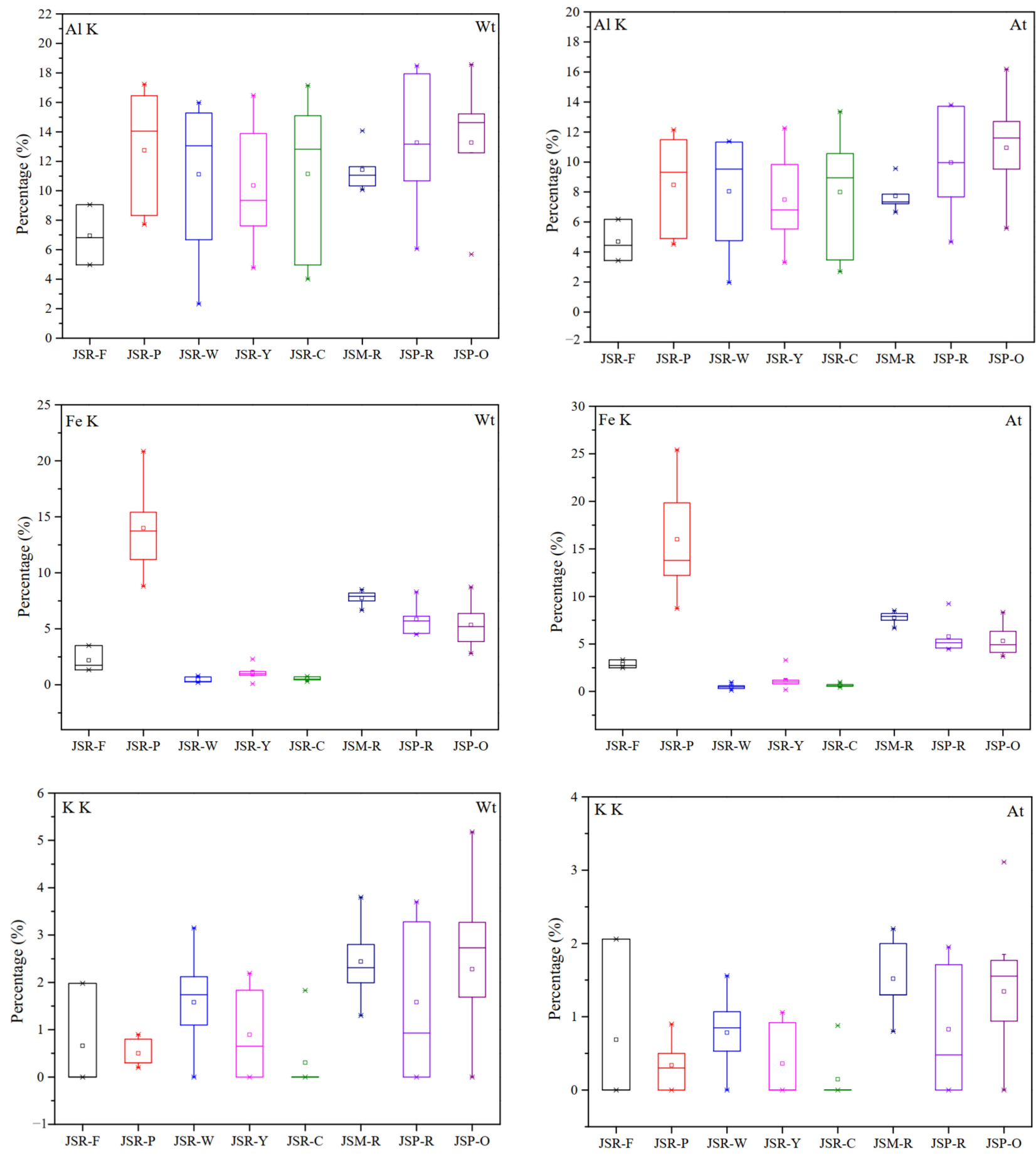

Figure 7. The results of EDS analysis. (Wt represents the mass percent, and At represents the atomic percent).

\subsection{Trace Elements}

ICP-MS was used to determine the trace element characteristics of raw materials, mixtures, and finished samples of Jianshui purple pottery in Yunnan; the results are listed in Table 4. 
Table 4. ICP-MS test results of trace element concentrations of samples $\left(\mathrm{wt} \% / 10^{-6}\right)$.

\begin{tabular}{ccccccccccc}
\hline Sample No. & $\mathbf{C r}$ & $\mathbf{N i}$ & $\mathbf{C u}$ & $\mathbf{Z n}$ & $\mathbf{P b}$ & $\mathbf{V}$ & $\mathbf{M n}$ & $\mathbf{S r}$ & $\mathbf{R b}$ & $\mathbf{Z r}$ \\
\hline JSP-O & 90.95 & 39.24 & 143 & 96.96 & 31.35 & 119.4 & 201 & 41.59 & 89.11 & 315.9 \\
JSP-R & 99.52 & 55.14 & 157.3 & 102.1 & 31.99 & 136.7 & 140.5 & 42.11 & 81.59 & 324.7 \\
JSM-R & 90.9 & 33.24 & 35.09 & 109.2 & 31.08 & 143.8 & 247.9 & 38.7 & 80.73 & 285.2 \\
JSR-C & 65.01 & 19.73 & 67.69 & 45.2 & 30.14 & 101.2 & 28.04 & 34 & 138.1 & 307.8 \\
JSR-F & 70.24 & 26.69 & 15.66 & 82.32 & 12.38 & 106.7 & 84.25 & 26.72 & 81.35 & 273.1 \\
JSR-P & 147.3 & 152.3 & 78.86 & 374.1 & 62.22 & 353.8 & 277.7 & 468.2 & 30.78 & 293.4 \\
JSR-W & 67.72 & 18.06 & 26.29 & 53.11 & 21.9 & 87.92 & 92 & 31.3 & 138.1 & 386.7 \\
JSR-Y & 53.47 & 10.65 & 21.46 & 32.19 & 21.56 & 99.85 & 28.94 & 21.88 & 112.7 & 330 \\
Background values & 127 & 81.3 & 56 & 76.3 & 14 & 143 & 1090 & 382 & 108 & 148 \\
\hline
\end{tabular}

The background value is the elemental abundance of the global crust [21].

Similar to the previous results, the trace element concentrations of JSR-P in the raw material samples showed different characteristics from the other four samples. The concentration of each trace element in JSR-P except $\mathrm{Rb}$ and $\mathrm{Zr}$ was much higher than that of the other clay samples. The concentrations of trace elements except $\mathrm{Zr}$ in the other samples were lower than or close to the concentrations in the crust, indicating that the raw material composition of the pottery was close to the natural composition of the earth. By comparing the test results of JSM-R with JSP-R and JSP-O, the concentration changes of trace elements in pottery before and after firing could be found. In the fired pottery, the concentrations of $\mathrm{Cr}, \mathrm{Pb}$, and $\mathrm{Rb}$ remained almost unchanged, the concentration of $\mathrm{Cu}$ increased significantly, the concentrations of $\mathrm{Ni}, \mathrm{Sr}$, and $\mathrm{Zr}$ increased slightly, and the concentrations of $\mathrm{Zn}, \mathrm{V}$, and Mn decreased slightly. Except for Mn and $\mathrm{Rb}$, the concentrations of trace elements in the reducing flame product were slightly higher than that of the oxidizing flame product. This can be attributed to the higher firing temperature of the oxidation firing method.

\subsection{Dissolution of Trace Elements}

Potteries are usually used as cups or bowls for humans' eating and drinking, which need to meet the standards of health. There are many materials used as food-contact containers such as plastic, stainless steel, paper, and so on. The dissolution of trace elements in kitchen utensils must not adversely affect human health. Consequently, the dissolution of trace elements is usually used as the standard of kitchen utensils' healthy qualification. Guan has completed the detection of the amount of $\mathrm{Cd}$ and $\mathrm{Pb}$ dissolution of Yunnan Jianshui purple pottery's raw material. The results showed that the dissolution of $\mathrm{Cd}$ was $0 \mathrm{mg} / \mathrm{L}$, and the dissolution of $\mathrm{Pb}$ in the fired products was in the range $0.039-0.053 \mathrm{mg} / \mathrm{L}$, both of which were lower than the requirements for food-contact materials [10].

According to the national standards of China for ceramic cooking utensils, the dissolution of trace elements in ceramic products were extracted by immersing samples in a solution of $4 \%$ acetic acid by volume at $(22 \pm 2){ }^{\circ} \mathrm{C}$ for $24 \mathrm{~h} \pm 20 \mathrm{~min}[22,23]$. Based on the practical application of pottery, three groups of dissolution tests were designed to simulate different use scenarios: (1) steeping at room temperature $(22+2){ }^{\circ} \mathrm{C}$ for $24 \mathrm{~h}$ to simulate daily holding drinking water, (2) heating the extract to boiling and pouring into pottery, then steeping at room temperature $(22+2){ }^{\circ} \mathrm{C}$ for $24 \mathrm{~h}$ to simulate daily tea and coffee brewing, and (3) pouring the extract into pottery, heating it over an alcohol lamp to keep it boiling for $1 \mathrm{~h}$, stopping the heating, then steeping at room temperature $(22+2){ }^{\circ} \mathrm{C}$ for $23 \mathrm{~h}$ to simulate daily cooking. After the immersion of each group of solutions was completed, the extracts were held in bottles, which had been rinsed with distilled water. Before each group of tests, the purple pottery cups were washed with a weak alkaline food utensil washing solution, then washed five times with distilled water, dried, and prepared for use. As shown in Figure 8, two standard and qualified Jianshui purple pottery finished products were chosen as samples. Figure 8 a shows the process of heating the oxidizing flame product using asbestos mesh and an alcohol lamp, and Figure 8b shows the heating process of the reducing flame product. Figure $8 \mathrm{c}$ shows the process of leaching and extracting the dissolution from the purple pottery cup vessel. 


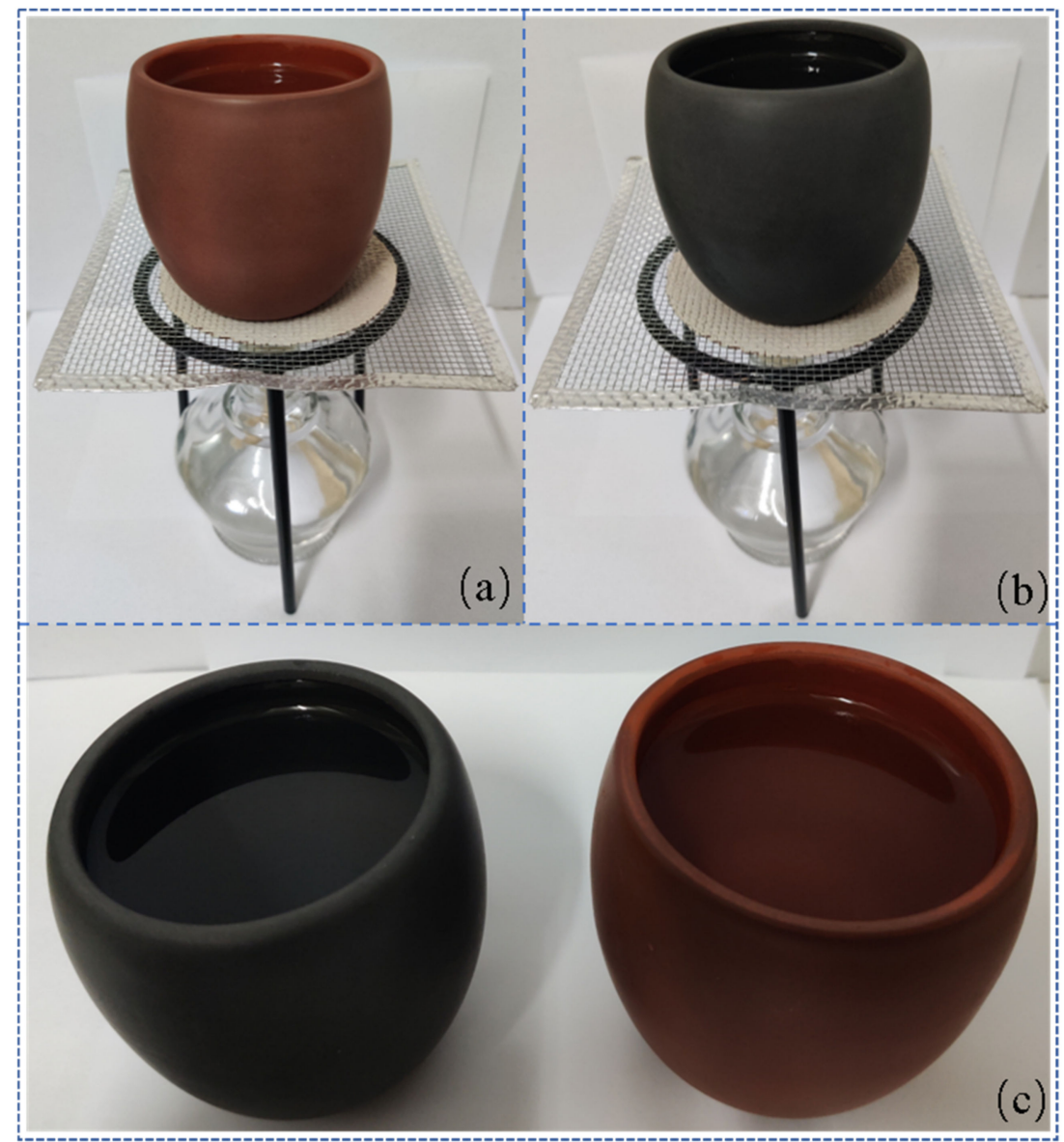

Figure 8. Dissolution tests of purple pottery $(\mathbf{a}, \mathbf{b})$ indicate heating oxidizing and reducing purple pottery cup to simulate daily cooking, respectively, and (c) shows the extraction process.

After the six sets of extracts were collected, all samples' trace element content was measured using the ICP-MS method. Test results are shown in Table 5, O-1 and R-1 are the result of the oxidizing flame product and the reducing flame product under use scenarios (1). Similarly, O-2 and R-2 are that under situation (2) and O-3 and R-3 are that under situation (3). The values of standards of drinking water (SODW) indicate the limit value of the content of trace elements in drinking water [24].

Table 5. Trace element dissolution of purple pottery cups measured by ICP-MS (mg/L).

\begin{tabular}{cccccccc}
\hline Trace Element & $\mathbf{P b}$ & $\mathbf{C d}$ & $\mathbf{C r}$ & $\mathbf{S e}$ & $\mathbf{F e}$ & $\mathbf{M n}$ & $\mathbf{C u}$ \\
\hline O-1 & 0.0004 & 0 & 0.0026 & 0.0005 & 0.0729 & 0.001 & 0.0047 \\
$\mathrm{R}-1$ & 0.0011 & 0.0003 & 0.003 & 0.0007 & 0.0863 & 0.0068 & 0.0038 \\
$\mathrm{O}-2$ & 0 & 0.0001 & 0.0033 & 0.0008 & 0.1014 & 0.0032 & 0.0023 \\
$\mathrm{R}-2$ & 0.0004 & 0 & 0.0032 & 0.0009 & 0.1196 & 0.0061 & 0.0021 \\
O-3 & 0 & 0.0001 & 0.0049 & 0.0012 & 0.1658 & 0.0019 & 0.0056 \\
$\mathrm{R}-3$ & 0 & 0 & 0.0049 & 0.0009 & 0.137 & 0.0056 & 0.002 \\
SODW & 0.01 & 0.005 & 0.05 & 0.01 & 0.3 & 0.1 & 1 \\
\hline Trace Element & $\mathbf{Z n}$ & $\mathbf{S b}$ & $\mathbf{B a}$ & $\mathbf{B e}$ & $\mathbf{B}$ & $\mathbf{N i}$ & $\mathbf{A g}$ \\
\hline O-1 & 0.0155 & 0.0008 & 0.0112 & 0 & 0.0006 & 0.0004 & 0.0001 \\
$\mathrm{R}-1$ & 0.0263 & 0.0014 & 0.0172 & 0.0002 & 0.0026 & 0.0005 & 0.0001 \\
O-2 & 0.0353 & 0.0006 & 0.0067 & 0.0001 & 0.0441 & 0.0005 & 0 \\
R-2 & 0.0355 & 0.0009 & 0.0122 & 0.0001 & 0.0438 & 0.0005 & 0 \\
O-3 & 0.011 & 0.0011 & 0.0046 & 0.0001 & 0.0078 & 0.0011 & 0 \\
R-3 & 0.0126 & 0.0012 & 0.0115 & 0.0002 & 0.0077 & 0.0012 & 0 \\
SODW & 1 & 0.005 & 0.7 & 0.002 & 0.5 & 0.02 & 0.05 \\
\hline
\end{tabular}


A national standard of China on food-contact ceramic products stipulates the permissible limit value of lead and cadmium dissolution in any single product: $\mathrm{Pb} \leq 0.5 \mathrm{mg} / \mathrm{L}$, $\mathrm{Cd} \leq 0.25 \mathrm{mg} / \mathrm{L}$ [22]. Additionally, another standard on ceramic cooking utensils also stipulates the permissible limit value of lead and cadmium dissolution: $\mathrm{Pb} \leq 3.0 \mathrm{mg} / \mathrm{L}$, $\mathrm{Cd} \leq 0.3 \mathrm{mg} / \mathrm{L}$ [25]. It can be seen that the dissolution of $\mathrm{Pb}$ and $\mathrm{Cd}$ of the Chinese Jianshui purple pottery cups were far below the limits of the relevant standards for ceramic products utensils. This product meets the health and hygiene standards and can be used as tableware and cookware.

\section{Discussion}

The pottery embryo, made of clay mud, is a powdered material that will be sintered to a dense body by firing at high temperatures. Increasing the firing temperature as well as increasing the firing time will result in improved performance such as the bending modulus, modulus of rupture (bending strength), density, and shrinkage percentage of the pottery $[26,27]$. The driving force of sintering is surface energy. Sintering can be divided into two categories: sintering with the participation of a liquid phase and pure solid phase sintering. Because the pottery embryo body composition contains potassium oxide and other fluxes, it can lower the sintering temperature and expand the sintering range. Therefore, purple pottery will form a liquid phase during the firing process, which in turn can promote sintering. The sintering process is of great importance for pottery production.

According to the experimental results, the main chemical compositions of the Jianshui purple pottery's raw ore are $\mathrm{SiO}_{2}, \mathrm{Al}_{2} \mathrm{O}_{3}, \mathrm{Fe}$, and $\mathrm{K}_{2} \mathrm{O}$, and purple soil is the main source of Fe. The SEM images of the raw ore samples show obviously clay characteristics, with a large number of holes evenly distributed. The clay minerals are irregularly flaky, and the quartz is distributed in granular form. Due to the mixing and extrusion, the SEM image of the mixture sample shows that the structure is dense and compact. It can be seen from the SEM images of the finished pottery samples that the clay minerals have been sintered together, and many tiny holes are formed because (1) the gas inside the clay and generated from raw material clay minerals has not been exhausted during the firing process, (2) the formation of the liquid phase during sintering, and (3) the phase transformation of quartz particles at high temperatures and its equivalent shrinkage during cooling. The oxidation firing method fully oxidizes the Fe in the oxidizing flame product to ferric, which appears red. The Fe in the product of the reduction firing method is ferrous, so the reducing flame product appears black.

As shown in Figure 9, the composition changes of pottery before and after firing mainly show that the percentages of $\mathrm{SiO}_{2}$ and $\mathrm{Al}_{2} \mathrm{O}_{3}$ increase, and $\mathrm{Fe}$ and LOI decrease. The melting point of $\mathrm{SiO}_{2}$ is $1650{ }^{\circ} \mathrm{C}$, and the melting point of $\mathrm{Al}_{2} \mathrm{O}_{3}$ is $2054{ }^{\circ} \mathrm{C}$, which is much higher than the firing temperature of pottery. Most of the Fe is present in the silicate matrix and in the form of iron oxides [28]. The mixed clay composition contains small amounts of $\mathrm{K}_{2} \mathrm{O}, \mathrm{TiO}_{2}$, and $\mathrm{Na}_{2} \mathrm{O}$, which can be used as fluxes at high temperatures. Because of their presence, the iron oxides melt during the firing of the pottery and form a liquid phase. The formation of the liquid phase can promote densification because of the higher atom diffusion rates. Therefore, the melting of iron oxides to form the liquid phase will make the pottery embryo denser on the one hand, and cause the iron oxides in the pottery embryo to be melted and lost on the other hand. The chemical composition of the pottery embryo reaches a stable state after firing at high temperatures, and there is almost no LOI remaining. Consequently, after firing, the percentages of Fe and LOI in pottery embryos obviously decrease, while the percentage of other major compositions will slightly increase. 


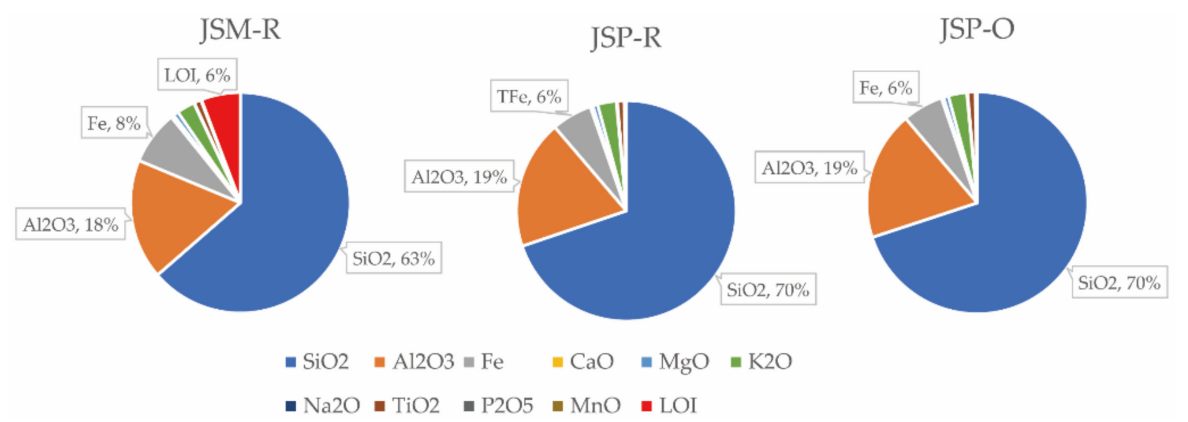

Figure 9. Comparison of Jianshui purple pottery clay and finished product composition.

G. A. DE LA FUENTE studied the chemical and mineralogical characterization of a set of 19 Aguada Portezuelo pottery sherds from Catamarca, Northwestern Argentina [29]. Particle-induced X-ray emission (PIXE) concentrations for major, minor, and trace elements was conducted. According to the composition characteristics such as elements ratio and elements concentrations, these samples were divided into three groups. The element concentration for the compositional groups are shown in Table 6.

Table 6. Trace element concentrations of three Aguada Portezuelo pottery sherds groups [29] (wt $\left.\% / 10^{-6}\right)$.

\begin{tabular}{ccccccccccc}
\hline Group & $\mathbf{C r}$ & $\mathbf{N i}$ & $\mathbf{C u}$ & $\mathbf{Z n}$ & $\mathbf{P b}$ & $\mathbf{V}$ & $\mathbf{M n}$ & $\mathbf{S r}$ & $\mathbf{R b}$ & $\mathbf{Z r}$ \\
\hline 1 & 127.80 & 94.29 & 294.8 & 423.36 & 174.65 & 845.18 & 173900 & 762.6 & 199.91 & 324.56 \\
2 & 154.34 & 111.28 & 191 & 423.78 & 235.26 & 384.29 & 4500 & 580.49 & 182.30 & 418.51 \\
3 & 133.11 & 121.89 & 716.89 & 372.67 & 198.06 & 376.02 & 2100 & 309.86 & 232.45 & 298.45 \\
\hline
\end{tabular}

K. B. Dasari et al. detected element concentrations of six representative ancient potteries from Srikakulam, Visakhapatnam, and East Godavari [30]. The test results of his research are as shown in Table 7. Part of the data was missing because their concentrations were below the detection limit.

Table 7. Trace element concentrations of six groups of ancient potteries [30] $\left(\mathrm{wt} \% / 10^{-6}\right)$.

\begin{tabular}{cccccccccc}
\hline Group & $\mathbf{C r}$ & $\mathbf{N i}$ & $\mathbf{C u}$ & $\mathbf{Z n}$ & $\mathbf{V}$ & $\mathbf{M n}$ & $\mathbf{S r}$ & $\mathbf{R b}$ & $\mathbf{Z r}$ \\
\hline 1 & 247 & 54 & 28 & 108 & 103 & 698 & 131 & 90 & 121 \\
2 & 292 & 44 & 46 & 112 & 102 & 790 & 132 & 84 & $\backslash$ \\
3 & 268 & 35 & 54 & 109 & 104 & 738 & 110 & 115 & 156 \\
4 & 301 & 43 & 32 & 137 & 106 & 721 & $\backslash$ & 101 & 142 \\
5 & 203 & 68 & 58 & 48 & 99 & 581 & 89 & 150 & $\backslash$ \\
6 & 221 & 65 & 39 & 92 & 86 & 515 & 96 & 88 & 106 \\
\hline
\end{tabular}

As a food utensil, pottery should not contain too many trace elements, otherwise it will inevitably pose a threat to the health of the users. The concentrations of trace elements in pottery are closely related to its place of origin, materials, and production process. As shown in Figure 10, the trace element content of pottery from Aguada Portezuelo(P1) and K. B. Dasari's study(P2) was averaged to compare the trace element levels of Jianshui purple pottery. Overall, Jianshui purple pottery showed far lower concentrations, which indicate that it has advantages in terms of human health.

Therefore, the low trace element content level of Jianshui purple pottery can also be reflected in its dissolution. Compared to the standard for drinking water, the trace element content of the extracts from the purple pottery cups, whether at room temperature, high temperature, or after cooking, were all far below the limit for drinking water. To sum up, the level of trace elements leached from Jianshui purple pottery cups is very low, and it is fully in line with human health standards when it is used as tableware and cooking utensils. 


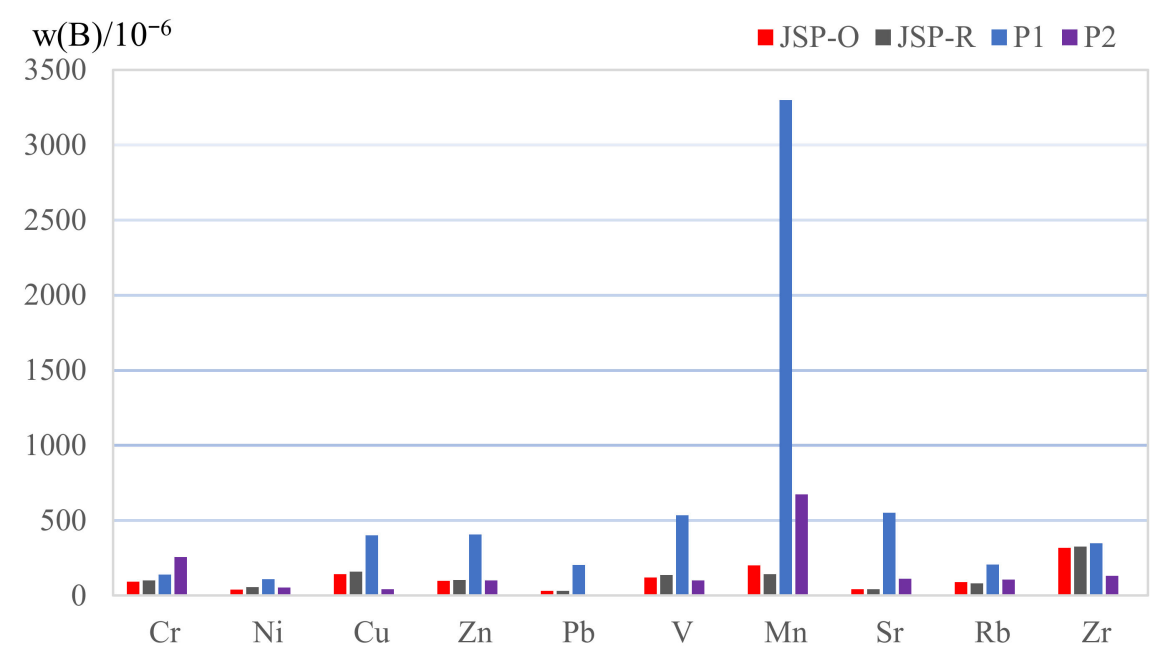

Figure 10. Comparison of trace element contents in different potteries (P1 means potteries from Aguada Portezuelo, and P2 means potteries in K. B. Dasari's study).

\section{Conclusions}

1. The firing temperature of Jianshui purple pottery is $1140-1160{ }^{\circ} \mathrm{C}$, which would melt iron oxides in the in the presence of fluxes, so it leads to the loss of Fe. After the high temperature firing makes the pottery embryo reach a stable state, LOI is reduced to almost nonexistent. Therefore, the main change in the chemical composition of Jianshui purple pottery before and after firing is reflected in the decrease in Fe and LOI content. By firing at high temperature for a long time, most of the impurities in Jianshui purple pottery are melted and then removed and especially the sintering effect, giving it distinguished performance and strength.

2. The level of trace elements contained in Jianshui purple pottery is very low compared with other potteries, which is related to the ratio of raw materials, its high firing temperature, and continuous improvement of the manufacturing process.

3. As a food-contact utensil, the trace element dissolution of Jianshui purple pottery is very low in various use scenarios, which proves that it can be widely and healthily used as cooking utensil and container.

Exquisite pottery is a monumental treasure in the history of human civilization, and the craft of pottery making is a skill that has been continuously passed down and refined in the development of human civilization. In this work, Chinese Jianshui purple pottery's chemical composition, SEM image, trace elements, and dissolution tests were conducted. The results show that Jianshui purple pottery is an excellent, widely-used, and healthy foodcontact utensil and container. According to our research, the manufacturing process, raw material proportioning, and composition changes during purple pottery's firing process can be obtained, which can be used as a theoretical basis for improving pottery production.

Author Contributions: Conceptualization, C.L., H.X. and L.N.; methodology, H.W., Y.H.; software, H.W.; formal analysis, C.L. and Y.H.; investigation, C.L., H.X. and L.N.; resources, H.X.; data curation, H.W. and Y.H.; writing-original draft preparation, C.L.; writing-review and editing, H.W. and Y.H.; supervision, L.N.; project administration, C.L., H.X. and L.N.; funding acquisition, C.L. and L.N. All authors have read and agreed to the published version of the manuscript.

Funding: This research was funded by the National Natural Science Foundation (Grant No. 41572254) and the scientific research planning project of Jilin Provincial Education Department (Grant No. JJKH20200278KJ).

Data Availability Statement: The data presented in this study are all available in this paper, and the data of EDS presented in this study are available on request from the corresponding author. 
Acknowledgments: The authors are grateful to Jianshui Purple Pottery Research Association of Jianshui County, Yunnan, China, for providing information on the background of purple pottery and the materials for the experiments in this study.

Conflicts of Interest: The authors declare no conflict of interest.

\section{References}

1. Pang, Q. Pottery Is Medium: Another Interpretation to the Prehistoric Pottery Civilization; Lanzhou University: Lanzhou, China, 2015.

2. Jordan, P.; Gibbs, K.; Hommel, P.; Piezonka, H.; Silva, F.; Steele, J. Modelling the diffusion of pottery technologies across Afro-Eurasia: Emerging insights and future research. Antiquity 2016, 90, 590-603. [CrossRef]

3. $\mathrm{Xu}, \mathrm{J}$. Viewing the Changes of Ancient National Culture in Yunnan Dianzhong Region from Pottery; Minzu University of China: Beijing, China, 2016.

4. McGovern, P.E.; Zhang, J.; Tang, J.; Zhang, Z.; Wang, C. Fermented beverages of pre- and proto-historic China. Proc. Natl. Acad. Sci. USA 2005, 101, 17593-17598. [CrossRef] [PubMed]

5. Tite, M.S. Determination of the Firing Temperature of Ancient Ceramics by Measurement of Thermal Expansion. Nature 2007, 11, 131-143.

6. Meng, Q. Discussion on the Firing Temperature of Prehistoric Pottery in Haidai Region; Shandong University: Jinan, China, 2019.

7. Yu, Y. Comparative Study on Early Pottery from Typical Sites in Southern China; Jingdezhen Ceramic Institute: Jingdezhen, China, 2011.

8. Wang, F.; Chen, S. Analysis of Chemical Composition and Physical Properties of Prehistoric Pottery in Beiqian Ruins. East Asia Archaeol. 2013, 1, 137-153.

9. $\mathrm{Xu}, \mathrm{Z}$. The Significance of Pottery Chemical Composition Analysis in Neolithic Archaeological Research. N. Culrural Relics 2004, 4, 101-106.

10. Guan, Z. The Characteristics of Mineral Raw Materials in Built Water Purple Pottery, Qinzhou Ningxing Pottery and Rongchang Pottery; Chengdu University of Technology: Chengdu, China, 2018.

11. Ma, X. Four Famous Ceramics in China; Yunnan Fine Arts Publishing House: Kunming, China, 2014.

12. Chen, C. An Analysis of the Developmental Characteristics of Jianshui Purple Pottery. Cult. J. 2016, 2, 179-182.

13. Martín-Márquez, J.; Rincón, J.M.; Romero, M. Effect of firing temperature on sintering of porcelain stoneware tiles. Ceram. Int. 2008, 34, 1867-1873. [CrossRef]

14. Martín-Márquez, J.; Torreb, A.; Aranda, M.; Rincón, J.; Romero, M. Evolution with Temperature of Crystalline and Amorphous Phases in Porcelain Stoneware. J. Am. Ceram. Soc. 2010, 92, 229-234. [CrossRef]

15. Wen, J.X.; Zeng, Q.G.; Lin-Shun, H.U.; Chen, Z.K.; Zhang, G.X. A Scanning Electron Microscope Analysis of the Blue-and-White Porcelain and the Famille-rose Porcelain Discovered on Shangchuan Island. J. Wuyi Univ. Nat. Sci. Ed. 2019, 33, 7-13.

16. Wang, H.F.; Bonner, B.P.; Carlson, S.R.; Kowallis, B.J.; Heard, H.C. Thermal Stress Cracking in Granite. J. Geophys. Res. Atmos. 1989, 94, 1745-1758. [CrossRef]

17. Podwórny, J.; Wojsa, J.; Wala, T. Variation of Poisson's ratio of refractory materials with thermal shocks. Ceram. Int. 2011, 37, 2221-2227. [CrossRef]

18. Thér, R. Identification of Pottery Firing Structures Using the Thermal Characteristics of Firing. Archaeometry 2013, 56, 78-99. [CrossRef]

19. Tite, M.S. Strength, Toughness and Thermal Shock Resistance of Ancient Ceramics, and Their Influence On Technological Choice. Archaeometry 2001, 43, 301-324. [CrossRef]

20. Ji, L.; Qiu, J.; Xia, Y.; Zhang, T. Micro-pore characteristics and methane adsorption properties of common clay minerals by electron microscope scanning. Acta Pet. Sin. 2012, 33, 249-256.

21. Li, T. Abundance of chemical elements in Chinese continental crust and its sedimentary layer and upper continental crust. Geochimica 1994, 2, 140-145.

22. Chongqing Hua Ceramic Industry, Co. Standard Permissible Limits of Lead and Cadmium Release from Ceramic Ware in Contact with Food; General Administration of Quality Supervision, Inspection and Quarantine of the People's Republic of China: Beijing, China, 2003; Volume GB 12651-2003, p. 8.

23. Guangxi Sanhuan Enterprise Group Co.; China Light Industry Ceramics Research Institute. Standard Testing Methods for Lead and Cadmium Release from Domestic Ceramic; General Administration of Quality Supervision, Inspection and Quarantine of the People's Republic of China: Beijing, China, 2002; Volume GB/T 3534-2002, p. 8.

24. National Institute of Environmental Health, China CDC. Standards for Drinking Water Quality; Ministry of Health of the People's Republic of China; China National Standardization Administration Committee: Beijing, China, 2006; Volume GB 5749-2006, p. 16.

25. Light Industry Ceramics Research Institute, Jingdezhen Ceramics School, Jingdezhen College of Higher Education. Standard Permissible Limits and Testing Method for Release of Lead or Cadmium from Ceramic Cookware; General Administration of Quality Supervision, Inspection and Quarantine of the People's Republic of China: Beijing, China, 2003; Volume GB 8058-2003, p. 8.

26. Bakar, N.A.; Daud, N.; Nor, S.M.M.; Mohamed, J.J.; Muhammad, N.M.N. The Effect of Firing Duration on Mambong Pottery. In Materials Characterization Using X-Rays And Related Techniques; Sulaiman, M.A., Ahmad, Z.A., Mohamed, J.J., Eds.; Amer Inst Physics: Melville, NY, USA, 2019; Volume 2068.

27. Kuang, M.; Wang, P.; Luo, Q.; Wei, Z.; Wei, Y.; Peng, H.; Xie, L. Porous pottery of sintered diatomite and adsorption performance of methylene blue. Bull. Chin. Ceram. Soc. 2016, 35, 2986-2989. 
28. Matsunaga, M.; Nakai, I. A study of the firing technique of pottery from Kaman-Kalehoyuk, Turkey, by synchrotron radiationinduced fluorescence X-ray absorption near-edge structure (XANES) analysis. Archaeometry 2004, 46, 103-114. [CrossRef]

29. Fuente, G.A.D.L.; Vera, S.D.; Dias, J.F.; Bertolino, S. Chemical and mineralogical characterization of Aguada Portezuelo pottery from Catamarca, north-western Argentina: PIXE, XRD and SEM-EDS studies applied to surface pre- and post-firing paints, slips and pastes. Archaeometry 2019, 62, 247-266. [CrossRef]

30. Dasari, K.B.; Acharya, R.; Ray, D.K.; Lakshmana Das, N. Application of PIXE for the determination of transition elements in the grouping study of archaeological clay potteries. X Ray Spectrom. 2017, 46, 180-185. [CrossRef] 